Fourth International Conference on Sustainable Construction Materials and Technologies http://www.claisse.info/Proceedings.htm

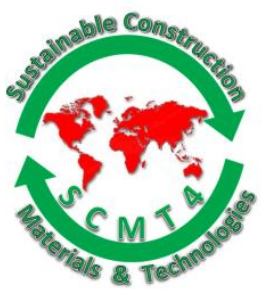

SCMT4

Las Vegas, USA, August 7-11, 2016

\title{
Applicability of Molten Slag and Porous Ceramic-Roof Tile Waste Aggregate to Massive Structural Concrete
}

\author{
Yuko Ogawa $^{1 \mathrm{a}}$, Akihiro Fujiyama ${ }^{1 \mathrm{~b}}$, Kenji Kawai ${ }^{1 \mathrm{c}}$, and Ryoichi Sato ${ }^{1 \mathrm{~d}}$ \\ 1Department of Civil and Environmental Engineering, Hiroshima University, JAPAN. \\ ${ }^{1 a}$ Email: <ogaway@hiroshima-u.ac.jp>, ${ }^{1 b}$ Email: <m153545@hiroshima-u.ac.jp>, ${ }^{1 c}$ Email: \\ <kkawai@hiroshima-u.ac.jp>, ${ }^{1 d}$ Email: <sator@hiroshima-u.ac.jp>.
}

\begin{abstract}
The aim of the present study is to investigate the applicability of molten slag derived from municipal waste (MS) and porous ceramic aggregate from roof tile waste (PCA) to massive structural concrete. For this aim, specimens sealed after casting were stored in a temperature-controlled room providing a high temperature history up to the age of 7 days and then at $20^{\circ} \mathrm{C}$. In addition, specimens were also prepared, which were stored at $20^{\circ} \mathrm{C}$ after casting.
\end{abstract}

Fine aggregate was replaced with MS at 30vol.\% and/or with PCA at 15vol.\%. Coarse aggregate was replaced with PCA at $12 \mathrm{vol} . \%$. All concretes prepared had a water to cement ratio of $40 \%$ and unit water content of $165 \mathrm{~kg} / \mathrm{m}^{3}$. The mechanical properties, shrinkage strain, and shrinkage-induced strain in reinforcement embedded longitudinally in a prismatic specimen were measured.

The results showed that compressive strengths of all concretes subjected to the temperature history ( $\mathrm{H}$ concrete) at the age of 28 days were more than $45 \mathrm{~N} / \mathrm{mm}^{2}$ although they were lower than those stored at $20^{\circ} \mathrm{C}$ (20-concrete). In addition, the high temperature history increased autogenous shrinkage of concrete without the waste aggregates by $30 \%$ at the temperature adjusted age of 150 days. However, the shrinkage in $\mathrm{H}$-concretes containing PCA and/or MS was almost the same as that of 20-concrete without the waste aggregates at the same temperature adjusted age, which means that the PCA and/or MS contributed to mitigating the shrinkage increased by the high temperature history. Besides, reinforcement strain induced by the shrinkage in concrete increased during the temperature rise and decreased during the subsequent temperature drop, and thereafter, increased again under $20^{\circ} \mathrm{C}$. The PCA and MS were effective in reducing the reinforcement strain at the temperature adjusted age of 150 days. Finally, the present waste aggregates have a potential to be applicable to massive structural concrete.

\section{INTRODUCTION}

Environmental conservation is one of the major issues in the world. The "reduce, reuse, recycle" called the three R's of waste management has been promoted in all fields of human activities more than ever before. The utilization of waste as materials of concrete can contribute to sustainable society in construction industry. 
Municipal waste is incinerated and the incinerated ash is molten at over $1,200^{\circ} \mathrm{C}$, which is called molten slag, in order to reduce the volume and to prolong the life of disposal facilities, and then molten slag is produced as granulated slag. Quite a few studies on the applicability of the molten slag were carried out [Kitatsuji and Fujii 1997, 1999; Sagawa et al. 2005; Matsuka et al. 2006], and then Japanese Industrial Standard (hereafter, JIS) A 5031 "Melt-solidified slag aggregate for concrete derived from municipal solid waste and sewage sludge" was established in 2006 to encourage the utilization of the molten slag. The molten slag, however, is limited to be used as a fine aggregate to plain and reinforced precast concrete members with the design compressive strength under $35 \mathrm{~N} / \mathrm{mm}^{2}$. Therefore, a lot more studies on properties of molten slag and concrete including the molten slag have been expected in order to use them widely. It was reported that the molten slag could have a latent hydraulicity due to a relatively high basicity [Kawamura et al. 2013], which means that wet curing is needed to improve the performance of concrete with the molten slag especially at the early age [Ogawa et al. 2013]. Structural performance of RC beams using molten slag was also investigated, which indicated the availability of the molten slags as fine aggregates of structural concrete [Nakarai et al. 2013].

On the other hand, about 150,000 tons of "Sekisyu Kawara" which is a roof tile made of clay is produced every year in the western Japan, and $10 \%$ of them is produced as waste due to cracking after sintering. The roof tile waste is also desired to be recycled, and some of them are used as aggregate for garden, pavement and so on. The porous ceramic roof tile waste has a crushing value of about $20 \%$, which is higher than that of artificial light weight aggregate used as internal curing agent. In addition, it has a water absorption of about 8-9\%, which is higher than normal aggregate. Making good use of these properties, the effects of the porous ceramic roof tile waste as an internal curing agent on the properties of concrete were investigated [Suzuki et al. 2009]. It has been reported that the porous ceramic roof tile waste is effective in improving the performance of concrete with portland blast furnace slag cement-type B in drying condition in terms of strength and porosity [Sato et al. 2011]. Additionally, the structural properties were also investigated and the results showed that the porous ceramic roof tile waste is applicable to structural slag cement concrete [Macharia et al. 2015].

Based on the results on the basic properties of concretes using these two waste aggregates mentioned above, they were reported to have applicability to structural concrete. Their applicability to massive structural concrete, however, has not been investigated yet, while autogenous shrinkage in concrete subjected to high temperature history can increase when compared with that at $20^{\circ} \mathrm{C}$ [Miyazawa et al. 2008].

Therefore, the present study aims at investigating the applicability of molten slag derived from municipal waste (hereafter, MS) and porous ceramic roof tile waste aggregate (hereafter, PCA) to massive structural concrete. For this aim, specimens sealed after casting were stored in a temperature-controlled room providing a high temperature history up to the age of 7 days and then at $20^{\circ} \mathrm{C}$. In addition, specimens were also prepared, which were stored at $20^{\circ} \mathrm{C}$ after casting.

\section{EXPERIMENTAL INVESTIGATION}

Materials. Cement used in this study was portland blast furnace slag cement-type B (hereafter, BB) with the density of $3.04 \mathrm{~g} / \mathrm{cm}^{3}$ and the specific surface area of $3,650 \mathrm{~kg} / \mathrm{m}^{3}$, which contained $40-45 \mathrm{mass} \%$ of ground granulated blast-furnace slag and met the standards set in JIS R 5211. Table 1 represents the properties of aggregates used in the present study. Crushed liparite sand and gravel, which met the standards set in JIS A 5005, were used as fine and coarse aggregates for reference concrete, respectively. Part of fine aggregate was replaced with MS and/or PCA, while part of coarse aggregate was replaced with PCA. PCA with size from $5 \mathrm{~mm}$ to $13 \mathrm{~mm}$ was used as coarse aggregate (hereafter, PCCA), while that from $1 \mathrm{~mm}$ to $5 \mathrm{~mm}$ was used as fine aggregate (hereafter, PCFA). Both PCFA and PCCA were immersed in water for more than 7 days before drying to saturated surface-dry condition to apply as internal curing agents. 
Table 1. Properties of Aggregates

\begin{tabular}{|c|c|c|c|c|}
\hline \multirow{2}{*}{ Materials } & Type & $\begin{array}{c}\text { Density } \\
\left(\mathrm{g} / \mathrm{cm}^{3}\right)\end{array}$ & $\begin{array}{c}\text { Water } \\
\text { absorption } \\
(\%)\end{array}$ & Notation \\
\hline \multirow{3}{*}{ Fine aggregate } & Crushed liparite sand & 2.60 & 2.28 & $\mathrm{~S}$ \\
\cline { 2 - 5 } & Porous ceramic fine aggregate & 2.26 & 8.92 & PCFA \\
\cline { 2 - 5 } & Molten slag fine aggregate & 2.77 & 0.42 & $\mathrm{MS}$ \\
\hline \multirow{2}{*}{ Coarse aggregate } & Crushed liparite gravel & 2.64 & 0.76 & $\mathrm{G}$ \\
\cline { 2 - 5 } & Porouc ceramic coarse aggregate & 2.27 & 9.20 & PCCA \\
\hline
\end{tabular}

Mixture Proportions. The mixture proportions of the concretes were listed in Table 2. The water to binder ratio (hereafter, W/C) and unit water content for all six concretes was $40 \%$ and $165 \mathrm{~kg} / \mathrm{m}^{3}$, respectively. Fine aggregate was replaced with MS at 30vol.\% and/or with PCFA at 15vol.\%. Coarse aggregate was replaced with PCCA at $12 \mathrm{vol} . \%$, where the amount of water absorbed into 12vol.\% PCCA was the same as that into $15 \mathrm{vol} . \%$ PCFA.

Table 2. Mixture Proportions

\begin{tabular}{|c|c|c|c|c|c|c|c|c|c|c|}
\hline \multirow{2}{*}{$\begin{array}{l}\text { Name of } \\
\text { specimen }\end{array}$} & \multirow{2}{*}{$\begin{array}{l}\mathrm{W} / \mathrm{C} \\
(\%)\end{array}$} & \multirow{2}{*}{$\begin{array}{l}\text { Air } \\
(\%)\end{array}$} & \multirow{2}{*}{$\begin{array}{l}\text { Sand to } \\
\text { aggregate } \\
\text { ratio } \\
(\%)\end{array}$} & \multicolumn{7}{|c|}{ Unit content $\left(\mathrm{kg} / \mathrm{m}^{3}\right)$} \\
\hline & & & & Water & Cement & $S$ & MS & PCFA & $\mathrm{G}$ & PCCA \\
\hline BB40 & \multirow{6}{*}{40} & \multirow{6}{*}{4.5} & \multirow{6}{*}{45.0} & 165 & 413 & 766 & 0 & 0 & 952 & 0 \\
\hline BB40MS & & & & 165 & 413 & 536 & 245 & 0 & 952 & 0 \\
\hline BB40PCFA & & & & 165 & 413 & 651 & 0 & 100 & 952 & 0 \\
\hline BB40MSPCFA & & & & 165 & 413 & 421 & 245 & 100 & 952 & 0 \\
\hline BB40PCCA & & & & 165 & 413 & 766 & 0 & 0 & 839 & 97 \\
\hline BB40MSPCCA & & & & 165 & 413 & 536 & 245 & 0 & 839 & 97 \\
\hline
\end{tabular}

Curing conditions. All specimens were sealed with aluminum adhesive tape after casting. Specimens were stored in a temperature-controlled room providing a high temperature history up to the age of 7 days and then at $20^{\circ} \mathrm{C}$. The temperature history was simulated the temperature at the point having the highest maximum temperature in massive concrete with same mixture proportion of BB40. Additionally, specimens were also prepared, which were stored at $20^{\circ} \mathrm{C}$ just after casting for comparison. These two temperature histories were shown in figure 1 . H-concrete and 20-concrete represent concrete subjected to high temperature history and concrete stored at $20^{\circ} \mathrm{C}$ after casting, respectively. 


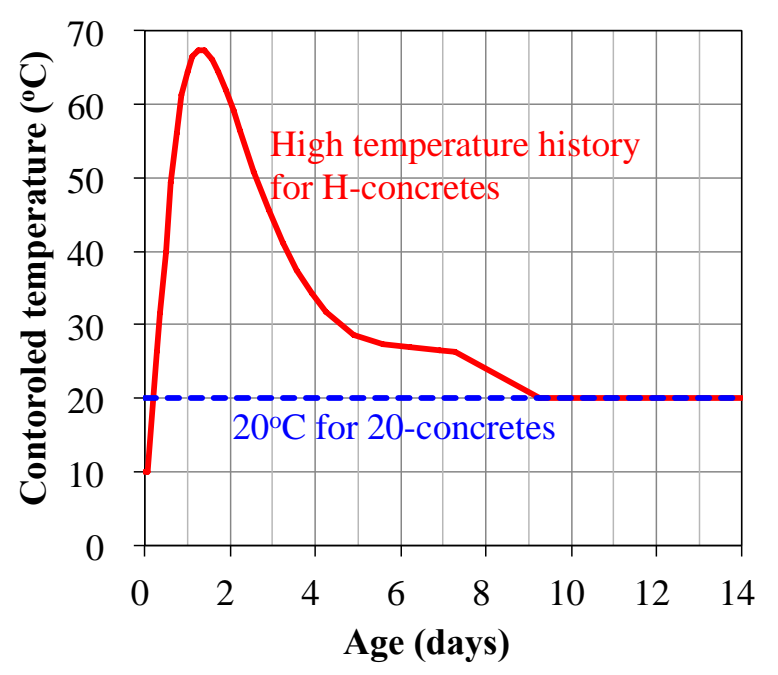

\section{Figure 1. Temperature History Subjected in the Present Study}

Items of investigations. Compressive strength, modulus of elasticity under compression and splitting tensile strength were measured for mechanical properties. The compressive strength and modulus of elasticity were tested at the ages of 1, 3, 7, 28, and 91 days conforming to JIS A 1108 and 1149, respectively, by using cylinder specimens with the diameter of $100 \mathrm{~mm}$ and the length of $200 \mathrm{~mm}$. Splitting tensile strength was tested at the ages of 3, 7, 28, and 91 days conforming to JIS A 1113 by using cylinder specimens with the diameter of $150 \mathrm{~mm}$ and the length of $150 \mathrm{~mm}$.

Autogenous shrinkage in concrete were investigated by using embedded gauges located at the center of prism specimens with the size of $100 \times 100 \times 400 \mathrm{~mm}$. Those were obtained by subtracting thermal strain from actual measured strain, where thermal strain was calculated with thermal expansion coefficient of 10 $\mathrm{x} 10^{-6} /{ }^{\circ} \mathrm{C}$.

Shrinkage-induced strain in reinforcement embedded longitudinally in a prismatic specimen was also measured. The prismatic specimen had the size of $100 \times 100 \times 1200 \mathrm{~mm}$, where a D19-bar with two gauges at the center was used for reinforcement.

\section{EXPERIMENTAL RESULTS AND DISCUSSION}

Mechanical properties. Temperature adjusted age determined by Eq.(1) (CEB-FIP MODEL CODE 1990) is applied to account the effect of temperature on the maturity of concrete.

$$
t_{e}=\sum_{i=1}^{n}\left[t_{i} \cdot \exp \left\{\begin{array}{ll}
13.65 & \frac{4000}{273+T\left(t_{i}\right) / T_{0}}
\end{array}\right\}\right]
$$

where $t_{e}$ is temperature adjusted age, $\Delta t_{i}$ is the number of days where a temperature $T$ prevails, and $T_{0}$ is 1 ${ }^{\circ} \mathrm{C}$.

Figure 2 shows compressive strength of concretes subjected to the high temperature history (hereafter, Hconcrete) and that of concrete cured at $20^{\circ} \mathrm{C}$ (hereafter, 20-concrete) with temperature adjusted age. According to the left side of figure 2, compressive strengths of BB40PCFA concrete subjected to high 
temperature history were almost the same as those of BB40 concrete, while the other concrete subjected high temperature history were slightly smaller than those of BB40 concrete. All compressive strengths of $\mathrm{H}$-concrete using waste aggregates, however, were same as or higher than $90 \%$ of compressive strength of BB40_H concrete represented by a black dashed line. It indicates that the decrease in compressive strength dose not pose a significant problem. Compared to the case of 20-concrete, compressive concrete of each $\mathrm{H}$ concrete was overtaken by 20-concrete at the temperature adjusted age of around 30 days. In addition, it can be seen that the compressive strength of concrete using waste aggregates can be affected by the high temperature history more than that of the reference concrete i.e. BB40 concrete.
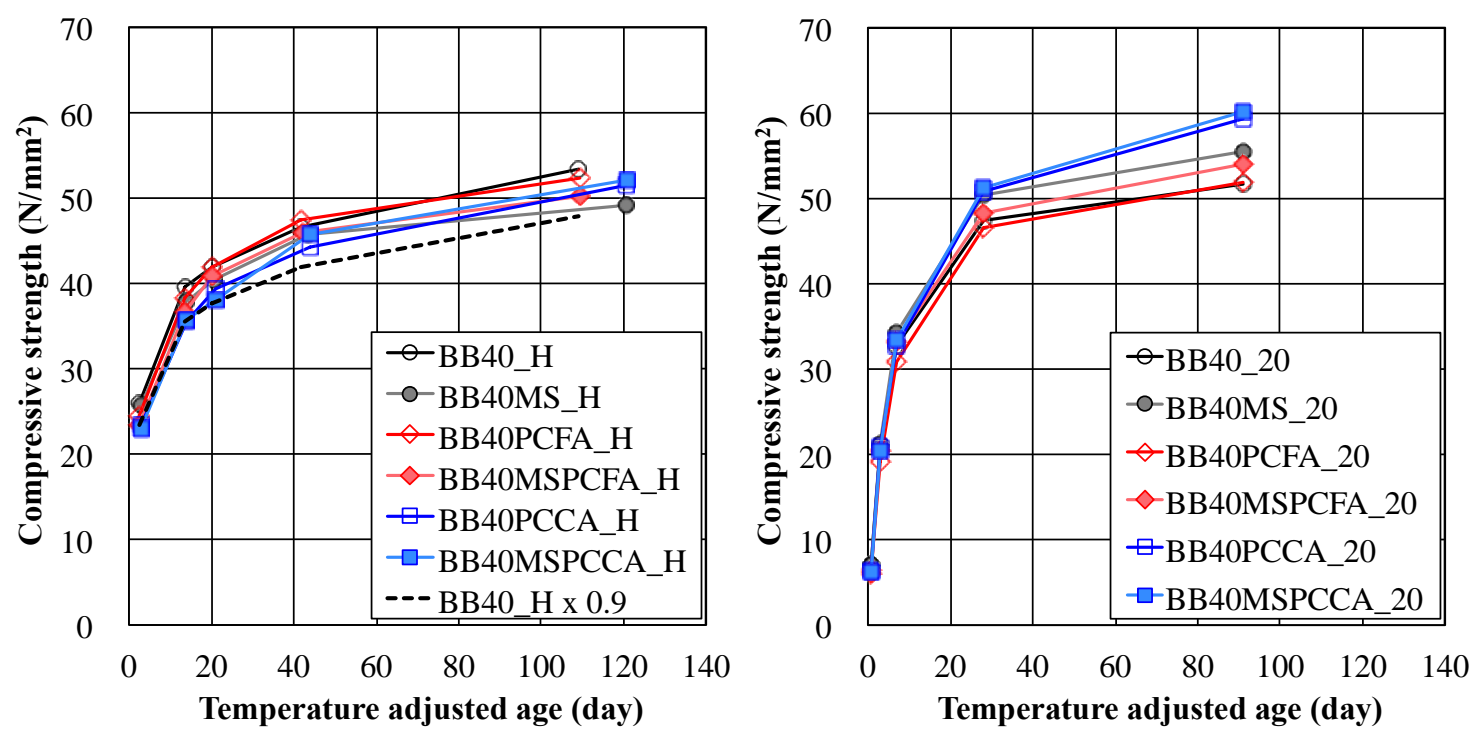

\section{Figure 2. Compressive Strength of Concrete (Left: Subjected to High Temperature History i.e. H-concrete, Right: Cured at $\mathbf{2 0}^{\circ} \mathrm{C}$ i.e. 20 -concrete)}

The relationship between compressive strength and modulus of elasticity and that between compressive strength and splitting tensile strength are shown in figure 3 and figure 4, respectively. Each green dashed line represents modulus of elasticity and splitting tensile strength which are calculated by Eq. (2) and Eq. (3), respectively, proposed by JSCE standard specification.

$$
\begin{aligned}
& E_{c}=\left\{\begin{array}{lr}
\left(2.2+\frac{f \infty_{c}^{\prime} 18}{20}\right) \times 10^{4} & \left(f^{\prime}{ }_{c}<30 \mathrm{~N} / \mathrm{mm}^{2}\right) \\
\left(2.8+\frac{f \infty_{c}^{\prime} 30}{33}\right) \times 10^{4} & \left(30 \leq f^{\prime}{ }_{c}<40 \mathrm{~N} / \mathrm{mm}^{2}\right) \\
\left(3.1+\frac{f \infty_{c}^{\prime} 40}{50}\right) \times 10^{4} & \left(40 \leq f^{\prime}{ }_{c}<70 \mathrm{~N} / \mathrm{mm}^{2}\right)
\end{array}\right\} \\
& f_{t}=0.23 f_{c}{ }_{c}^{2 / 3}
\end{aligned}
$$

According to figure 3, modulus of elasticity for the same compressive strength of concrete using waste aggregate was similar to that of BB40 concrete regardless of temperature, except for the case of 20-concrete with more than around $50 \mathrm{~N} / \mathrm{mm}^{2}$ of compressive strength. In that case, modulus of elasticity for the same compressive concrete with PCFA or PCCA was slightly lower than that for concrete without PCFA or 
PCCA. This is due to smaller modulus of elasticity of PCFA and PCCA than normal aggregate. By and large, the relationship between compressive strength and modulus of elasticity obtained by the present experiment was not affected significantly by either high temperature history or waste aggregates.

Splitting tensile strength for the same compressive strength of concrete using waste aggregate was also similar to that of BB40 concrete regardless of temperature. Similar to modulus of elasticity, it means the relationship between compressive strength and splitting tensile strength was not affected by either high temperature or waste aggregates.

Besides, both modulus of elasticity and splitting tensile strength calculated in this study were approximately equal to or higher than that obtained by JSCE. That is, MS, PCFA and PCCA can be said to have applicability to structural concrete even if concrete is subjected to high temperature history.
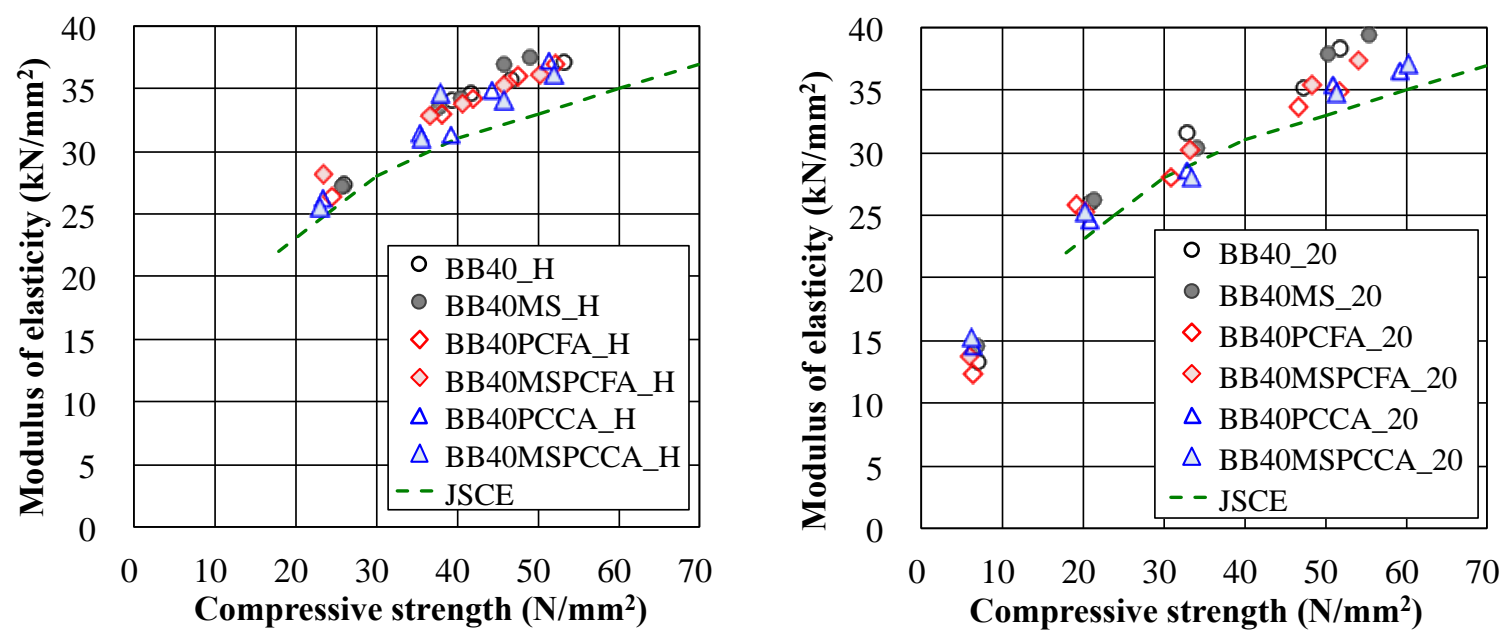

Figure 3. Relationship between Compressive Strength and Modulus of elasticity of concrete (Left: H-concrete, Right: 20-concrete)
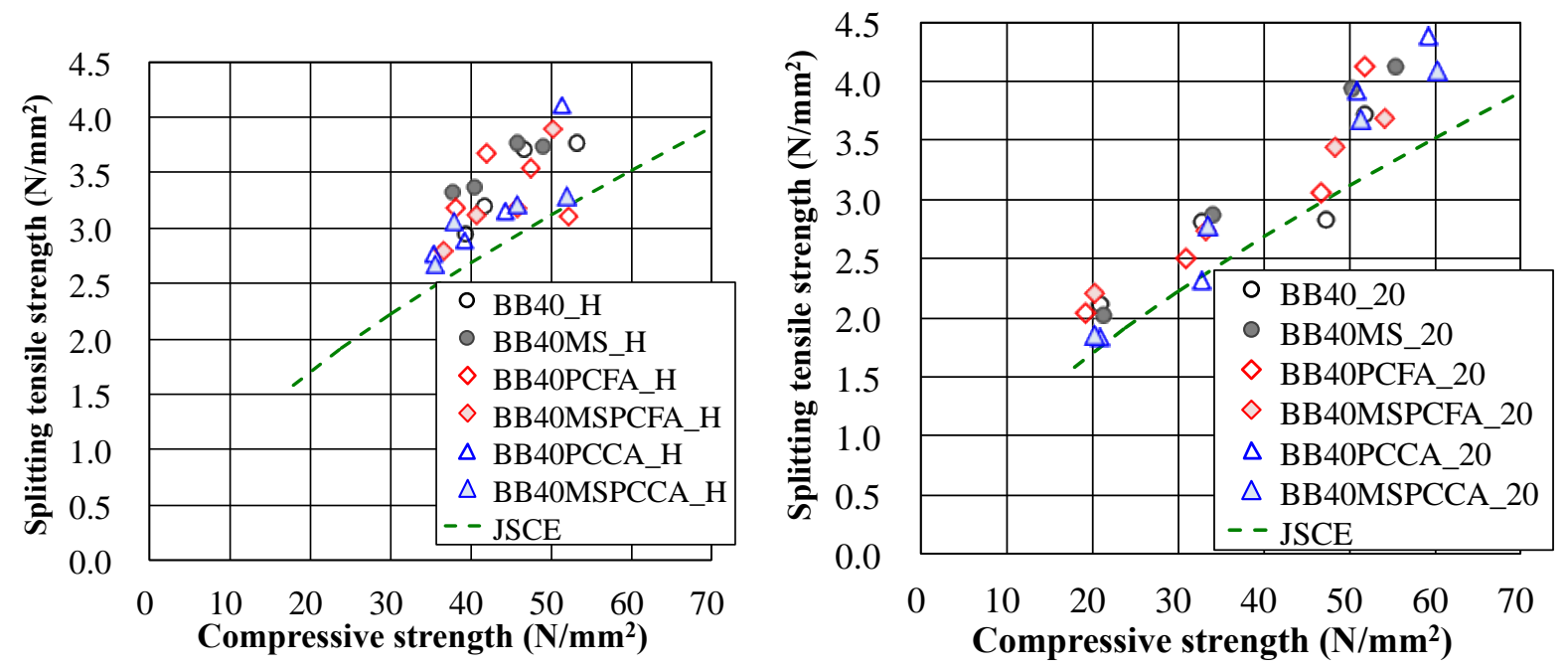

Figure 4. Relationship between Compressive Strength and Modulus of elasticity of Concrete (Left: H-concrete, Right: 20-concrete) 
Autogenous shrinkage in concrete. Figure 5 demonstrates autogenous shrinkage strain in concrete, which was obtained by subtracting thermal strain from measured free strain, where thermal expansion coefficient of concrete was assumed to be $10 \times 10^{-6} /{ }^{\circ} \mathrm{C}$. The data is plotted from the point where reinforcement stress appears. Autogenous shrinkage in BB40 concrete subjected to high temperature history was larger than any other concrete, while autogenous shrinkage in BB40 concrete was almost the same as that in concrete using MS and/or PCA in the case of 20-concrete. According to figure 6, which demonstrates the effect of high temperature on autogenous shrinkage in concrete, high temperature history increased the autogenous shrinkage in BB40 concrete with time up to around 30\%, while autogenous shrinkage in concretes using waste aggregates, except for BB40MSPCFA, were not affected remarkably by high temperature history. This may be due to the internal curing by using PCFA or PCCA, especially in the case of high temperature.
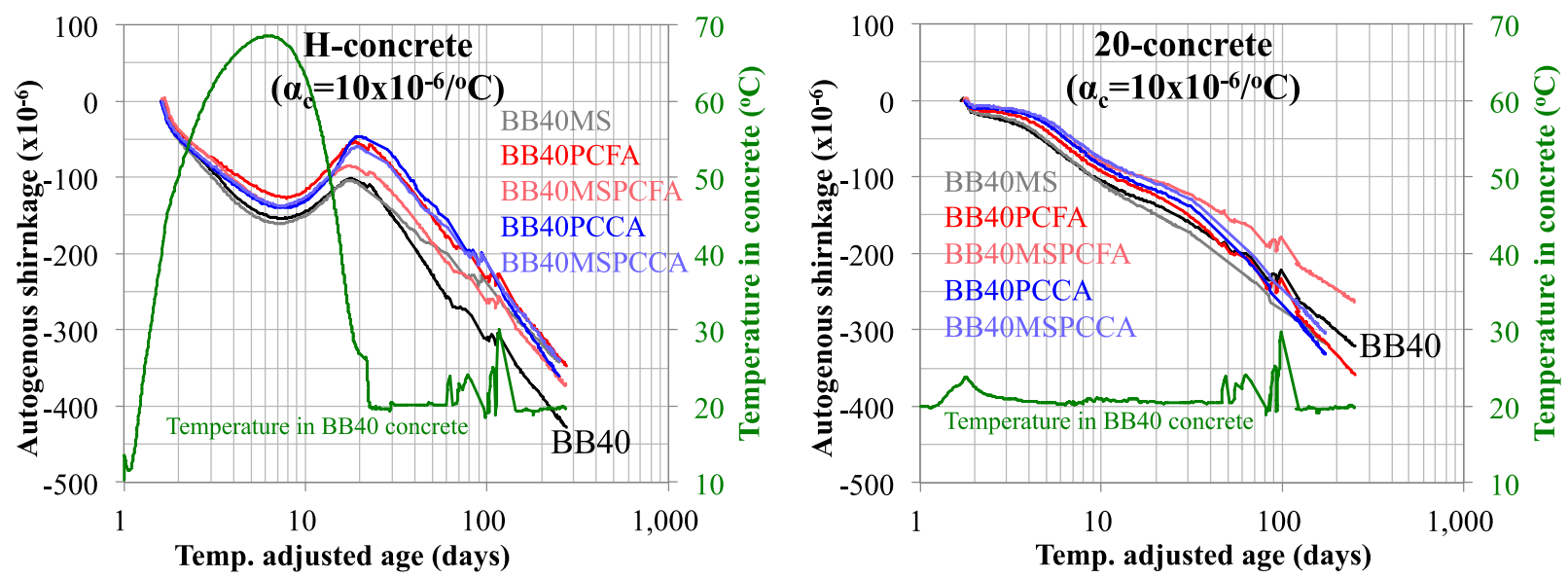

Figure 5. Autogenous Shrinkage and Temperature in Concrete Where Thermal Expansion Coefficient of Concrete was Assumed to be $10 \times 10^{-6} /{ }^{\circ} \mathrm{C}$ (Left: H-concrete, Right: 20concrete)

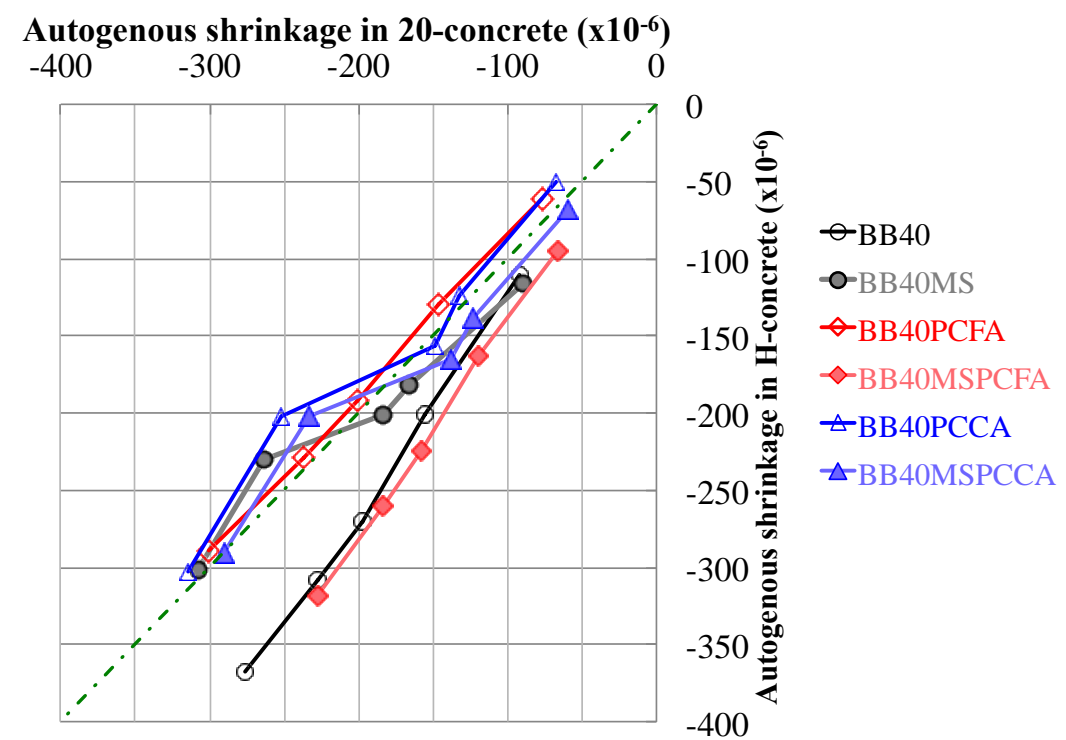

Figure 6. Effect of High Temperature History on Autogenous Shrinkage in Concrete 
Shrinkage-induced strain in reinforcement. Figure 7 illustrates reinforcement strain induced by shrinkage in concrete and temperature in BB40 concrete with temperature adjusted age. In the case of $\mathrm{H}$ concrete, the reinforcement increased during temperature rise and decreased during subsequent temperature drop, and thereafter, increased again at $20^{\circ} \mathrm{C}$, while the reinforcement strain in 20-concrete kept increasing from the point where the reinforcement stress appeared. This should include the effect of the difference of thermal expansion coefficient between reinforcement and strain. However, further studies are needed in order to explain those tendencies clearly.
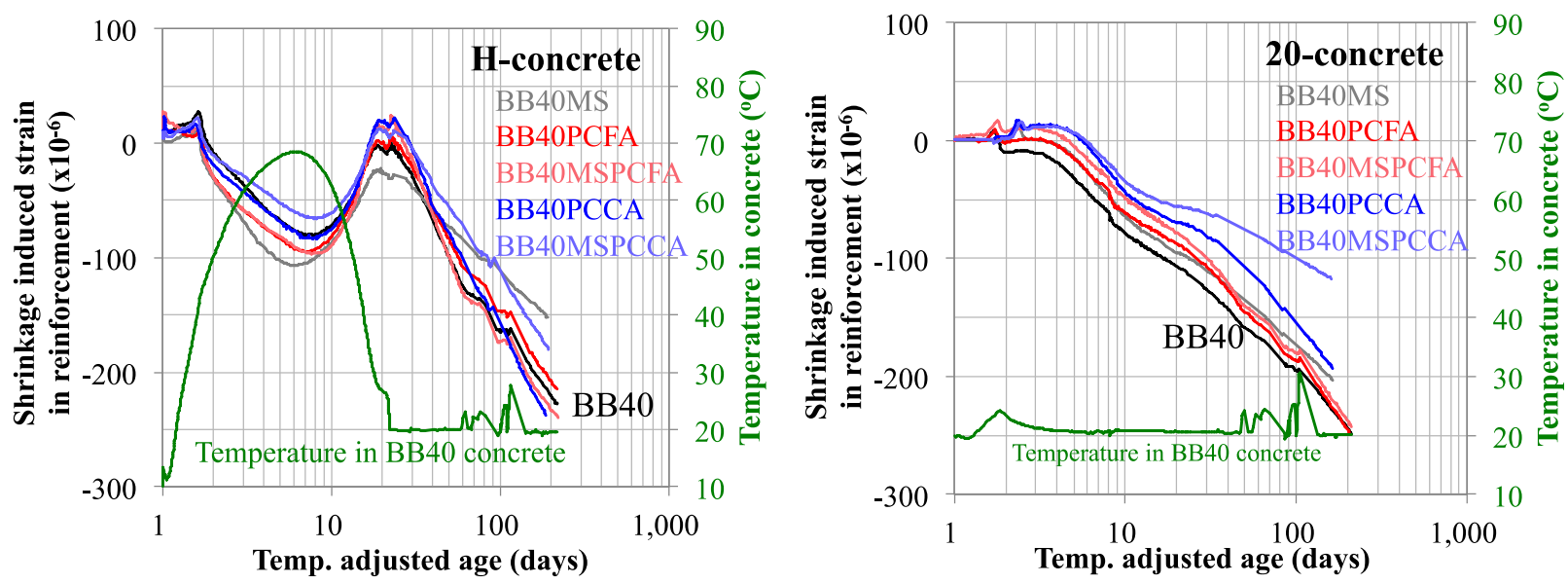

Figure 7. Shrinkage-induced Strain in Reinforcement and Temperature in Concrete (Left: H-concrete, Right: 20-concrete)

Shrinkage in reinforcement is listed in Table 3. The values between brackets indicate the ratios to shrinkage in $\mathrm{BB} 40$ cured at $20^{\circ} \mathrm{C}$. In the present experiment, reinforcement strain at the temperature adjusted age of 150 days was not affected significantly by high temperature history. The reinforcement strain in $\mathrm{H}$-concrete, however, kept increasing more rapidly than that in 20-concrete. It means that investigation for a longer time is required. In the case of 20-concrete, reinforcement strain in all concrete with waste aggregates was smaller than that in the reference concrete i.e. BB40, while in the case of $\mathrm{H}$-concrete, it was almost the same as or smaller than that in BB40. It can be suggested that MS and PCA have applicability to use for massive concrete structures.

Table 3. Shrinkage-Induced Strain in Reinforcement at the Temperature Adjusted Age of 7, 28, 91 and 150 Days with Ratios to BB40 Concrete Cured at $2^{\circ} \mathrm{C}$.

\begin{tabular}{|c|c|c|c|c|c|c|}
\hline 20-concrete & BB40_20 & BB40MS_20 & BB40PCFA_20 & BB40MSPCFA_20 & BB40PCCA_20 & BB40MSPCCA_20 \\
\hline 7 days & $(1.00)$ & $(0.79)$ & $(0.73)$ & $(0.52)$ & $(0.43)$ & $(0.32)$ \\
\hline 28 days & $(1.00)$ & $(0.85)$ & $(0.84)$ & $(0.78)$ & $(0.62)$ & $(0.48)$ \\
\hline 91 days & $(1.00)$ & $(0.85)$ & $(0.96)$ & $(0.93)$ & $(0.74)$ & $(0.48)$ \\
\hline 150 days & $-221 \quad(1.00)$ & $\begin{array}{ll}-197 \quad(0.89) \\
\end{array}$ & $(0.99)$ & $(0.96)$ & $(0.84)$ & $(0.52)$ \\
\hline $\mathrm{H}$-concrete & BB40_H & BB40MS_H & BB40PCFA_H & BB40MSPCFA_H & BB40PCCA_H & BB40MSPCCA_H \\
\hline 7 days & $(1.34)$ & $-100 \quad(1.68)$ & $(1.56)$ & $(1.62)$ & $(1.39)$ & $(1.11)$ \\
\hline 28 days & $(0.20)$ & $(0.28)$ & $(0.13)$ & $(0.08)$ & $-(0.02)$ & $(0.00)$ \\
\hline 91 days & $(0.74)$ & $(0.54)$ & $(0.65)$ & $(0.76)$ & $(0.74)$ & $(0.52)$ \\
\hline 150 days & $(0.88)$ & $(0.62)$ & $(0.82)$ & $(0.92)$ & $(0.96)$ & $(0.68)$ \\
\hline
\end{tabular}




\section{CONCLUSION}

The present study aims at investigating the applicability of MS and PCA to massive structural concrete using portland blast furnace slag cement type B. Concrete was subjected to high temperature history simulating the temperature in massive concrete structure, while concrete cured at $20^{\circ} \mathrm{C}$ was also investigated for comparison. The following conclusions can be drawn within the limit of the study.

When concrete were subjected to high temperature history, compressive strength concrete with MS and/or PCA was slightly smaller than the reference concrete by less than $10 \%$, while MS and PCA was effective in increasing the compressive strength of concrete cured at $20^{\circ} \mathrm{C}$.

Modulus of elasticity and splitting tensile strength of concrete with waste aggregate for the same compressive strength were almost the same as the reference concrete regardless of the presence or absence of high temperate history.

High temperature history increased autogenous shrinkage by around $30 \%$ in the case of the reference concrete at the temperature adjusted concrete age of 150 days. However, the shrinkage of $\mathrm{H}$-concretes containing PCA and/or MS were almost the same as that of 20-concrete without the waste aggregates at the same age, because the PCA and MS contributed to mitigating the shrinkage increased by the high temperature history.

Reinforcement strain induced by the shrinkage in concrete increased during the temperature rise and decreased during the subsequent temperature drop, and thereafter, increased again under $20^{\circ} \mathrm{C}$. The PCA and MS were effective in reducing the reinforcement strain at the temperature adjusted age of 150 days. Further studies are needed to clarify the tendency as well as investigate for a long time.

In summary, the present results suggested that the present waste aggregates have a potential to be applicable to massive structural concrete.

\section{REFERENCES}

Comité euro-international du béton and Fédération internationale de la précontrainte (1990). "CEB-FIP MODEL CODE 1990." Thomas Telford, 61-62.

Japanese Industrial Standard (JIS) A 1108. "Method of test for Compressive Strength of Concrete." Japanese Standards Association, 3 pages.

Japanese Industrial Standard (JIS) A 1113. "Method of Test for Splitting Tensile Strength of Concrete." Japanese Standards Association, 3 pages.

Japanese Industrial Standard (JIS) A 1149. "Method of Test for Static Modulus of Elasticity of Concrete." Japanese Standards Association, 3 pages.

Japanese Industrial Standard (JIS) A 5005. "Crushed Stone and Manufactured Sand for concrete.” Japanese Standards Association, 8 pages.

Japanese Industrial Standard (JIS) A 5031. "Melt-Solidified Slag Aggregate for Concrete Derived from Municipal Solid Waste and Sewage Sludge.” Japanese Standards Association, 16 pages. 
Japanese Industrial Standard (JIS) R 5211. "Portland blast-furnace slag cement." Japanese Standards Association, 7 pages.

Japan Society of Civil Engineers (2013). "Standard specification for concrete structures -2012, Design."

Kawamura, K., Ogawa, Y., Macharia, M. M., Nakarai, K., and Sato, R. (2013) "Properties of Concrete Containing a Molten Slag as Fine Aggregate." Proceedings of First International Conference on Concrete Sustainability, 252-259.

Kitatsuji, M., and Fujii, K. (1997). "Fundamental Studies on the Utilization of Melting Slag from Incineration Ash from Municipal Solid Waste as Fine Aggregate for Concrete." Transactions of the Japanese Society of Irrigation, Drainage and Reclamation Engineering, No.192, 1-8.

Kitatsuji, M., and Fujii, K. (1999). "Properties of Concrete Using Melting Slag from Municipal Solid Waste as Fine Aggregate for Concrete." Transactions of the Japanese Society of Irrigation, Drainage and Reclamation Engineering, No.200, 59-67.

Macharia, M. M., Ogawa, Y., Yamaguchi, K., Kawai, K., and Sato, R. (2015). "Flexural Crack Width of Reinforced Concrete Beams with Roof Tile Waste Aggregate." Proceedings of Thirteenth International Conference on Advances in Concrete Technology and Sustainability Issues, ACI SP-303, 83-101.

Matsuka, T., Sakai, K., Nakamura, T., and Kusanagi, S. (2006). "Flexure and Shear Behavior of Reinforced Concrete Beams Using Molten Slag from Industrial Waste." Doboku Gakkai Ronbunshuu E, Japan Society of Civil Engineers, Vol.62, No. 1, 159-173.

Miyazawa, S., Sato, R., and Sugiyama A. (2008). "Prediction Model for Autogenous Shrinkage of BlastFurnace Slag Cement Concrete at High-Temperature." Proceedings of the Japan Concrete Institute, Vol.30, No.1, 465-470.

Nakarai, K., Kawamura, K., Ogawa, Y., and Sato, R. (2013) "Structural Performance of RC Beams Containing Molten Slag as Fine Aggregate." Proceedings of First International Conference on Concrete Sustainability, 760-767.

Sagawa, Y., Kawabata, Y., Matsushita, H., Miyake, J., and Hiraki, S. (2005). "A study on Utilization of Molten Slag of Municipal Solid Waste as Fine Aggregate for Concrete." Doboku Gakkai Ronbunshu, Japan Society of Civil Engineers, No. 802/V-69, 171-180.

Ogawa, Y., Kawamura, K., Nakarai, K., and Sato, R. (2013). "Effect of Curing Condition on Basic Mechanical Properties of Concrete Containing a Molten Slag as Fine Aggregate." Proceedings of the Japan Concrete Institute, Vol.35, No.2, 1585-1590.

Sato, R., Shigematsu, A., Nukushina, T., and Kimura, T. (2011). "Improvement of Properties of Portland Blast Furnace Cement Type B Concrete by Internal Curing Using Ceramic Roof Material Waste.” Journal of Materials in Civil Engineering, Vol.23, Issue 6, 777-782.

Suzuki, M., Meddah, M. S., and Sato, R. (2009) "Use of porous ceramic waste aggregates for internal curing of high-performance concrete." Cement and Concrete Research, Vol. 39, Issue 5, 373-381. 